\title{
A PERCEPÇÃO DOCENTE SOBRE CONCEITOS, POLÍTICAS E PRÁTICAS INCLUSIVAS: UM ESTUDO DE CASO NO BRASIL
}

\author{
LA PERCEPCIÓN DOCENTE SOBRE CONCEPTOS, POLÍTICAS Y PRÁCTICAS \\ INCLUSIVAS: UN ESTUDIO DE CASO EN BRASIL
}

\section{THE PERCEPTION OF TEACHERS ON INCLUSIVE CONCEPTS, POLICIES AND PRÁCTICES. CASE STUDY IN BRAZIL}

\author{
Eladio SEBASITÁN-HEREDERO ${ }^{1}$ \\ Alexandra Ayach ANACHE ${ }^{2}$
}

\begin{abstract}
RESUMO: A educação inclusiva continua sendo um desafio e uma meta a ser alcançada em benefício da educação para todos, dentro da escola regular e do atendimento aos alunos que apresentam dificuldades de aprendizagem, sejam estes estudantes da educação especial ou não. Neste texto, apresenta-se um estudo de caso, de cunho qualitativo, realizado com 51 professores de escolas públicas do Mato Grosso do Sul, relacionado às suas percepções sobre conceitos, políticas e práticas inclusivas. Assim, os resultados apontam que, embora muitos docentes tenham os conceitos adquiridos, as sensações de descrédito, de falta de apoios e recursos ou de organização trazem implicações em suas construções sobre o tema. Estes elementos importantes configuram para esta amostra uma diferente forma de abordagem da inclusão que se divide entre ações e práticas educativas inclusivas e falta de respostas adequadas derivadas dessa construção de conceitos.
\end{abstract}

PALAVRAS-CHAVE: Educação inclusiva. Práticas educativas inclusivas. Políticas públicas inclusivas. Percepção docente.

RESUMEN: La educación inclusiva hoy en día sigue siendo un desafío y una meta a conseguir en beneficio de la educación para todos dentro de la escuela común y de la atención a los estudiantes que presentan dificultades de aprendizaje, sean estos alumnos de educación especial o no. El camino andado por Brasil ha sido largo, no obstante partimos del problema de si realmente esta se está desarrollando. Presentamos aquí un estudio de caso de corte cualitativo realizado con 51 profesores de colegios públicos de Mato Grosso do Sul (Brasil) sobre la construcción que hicieron de los diferentes conceptos envueltos y las percepciones dentro de esta trayectoria, encontrando que, a pesar de que muchos tienen los conceptos adquiridos, las sensaciones de desconfianza, de falta de apoyo y recursos o de organización son importantes, lo que sirve para que esta muestra se presente con dos formas

\footnotetext{
${ }^{1}$ Universidade Federal de Mato Grosso do Sul (UFMS), Campo Grande - MS - Brasil. Professor visitante estrangeiro, FAED/PPGEDU. ORCID: https://orcid.org/0000-0003-0293-4395. E-mail: eladio.sebastian@gmail.com

${ }^{2}$ Universidade Federal de Mato Grosso do Sul (UFMS), Campo Grande - MS - Brasil. Professora titular, FAED/PPGEDU. ORCID: https://orcid.org/0000-0002-7937-4448. E-mail: alexandra.anache@gmail.com
}

RIAEE - Revista Ibero-Americana de Estudos em Educação, Araraquara, v. 15, n. esp. 1, p. 1018-1037, maio 2020. e-ISSN: 1982-5587. DOI: https://doi.org/10.21723/riaee.v15iesp.1.13514 
diferentes de actuar, aquellos que realizan acciones y prácticas educativas y aquellos que no ofrecen respuestas adecuadas derivadas de esa construcción de conceptos.

PALABRAS CLAVE: Educación inclusiva. Prácticas educativas inclusivas. Políticas públicas inclusivas. Percepción docente.

ABSTRACT: Inclusive education stills a challenge and a goal to be achieved for the benefit of education for all, within the regular school and in the care of students who have learning difficulties, whether these being special education students or not. This text presents a qualitative case study conducted with 51 teachers from public schools in Mato Grosso do Sul, related to their perceptions of inclusive concepts, policies and inclusive practices. Thus, the results points out that, although many teachers have the acquired concepts, the sensations of discredit, lack of support and resources or organization have implications in their constructions on the subject. These important elements configure for this sample a different kind of approach to inclusion that is divides itself between inclusive educational actions and practices and lack of adequated answers derived from this construction of concepts.

KEYWORDS: Inclusive education. Inclusive educational practices. Inclusive public policies. Teacher perception.

\section{Introdução}

Depois de um longo e difícil caminho, as discussões sobre a educação inclusiva se intensificaram após a assinatura da Declaração de Salamanca (BRASIL, 1994). Esta, publicada após a Declaração de Educação para Todos, é considerada o marco na luta por princípios, políticas e práticas pela educação inclusiva. A Declaração forneceu diretrizes mundiais para reformas educacionais, embasando o princípio de igualdade de direito de todos, respeitando as diferenças e garantindo o acesso, permanência e formação nas escolas regulares.

Além disso, o documento ampliou os conceitos sobre necessidades educativas especiais, beneficiando não só crianças com algum tipo de deficiência, mas, também, crianças com dificuldades de aprendizagem de forma permanente ou temporária, afirmando, desta forma, que todo estudante tem direito de ser inserido em uma sala regular, sem que exista qualquer tipo de discriminação.Assim proclama que:

[...] as escolas regulares, seguindo esta orientação inclusiva, constituem os meios mais capazes para combater as atitudes discriminatórias, criando comunidades abertas e solidárias, construindo uma sociedade inclusiva e atingindo a educação para todos; além disso, proporcionam uma educação adequada à maioria das crianças e promovem a eficiência, numa óptima 
relação custo-qualidade, de todo o sistema educativo (BRASIL,1994, p. VIII).

A disseminação da educação inclusiva no Brasil teve um importante percurso legislativo, sendo o ano de 1996 decisivo com a proclamação da Lei de Diretrizes e Bases da Educação Nacional - LDBEN (BRASIL, 1996). Posteriormente viriam grandes avanços em prol da inclusão, mas em janeiro de 2016, quando entrou em vigor a Lei 13.146,Lei Brasileira de Inclusão da Pessoa com Deficiência - Estatuto da Pessoa com Deficiência (BRASIL, 2015), reafirmou-se que pessoas com deficiência tem direito à educação escolar com qualidade, com projetos visando ao maior desenvolvimento de todos os estudantes, garantindo, desta forma, o acesso pleno à educação. Concretamente, o artigo 28 desta lei proclama que o poder público deve garantir, criar, desenvolver, incentivar, acompanhar e avaliar aos estudantes neste processo de inclusão:

$\mathrm{V}$ - adoção de medidas individualizadas e coletivas em ambientes que maximizem o desenvolvimento acadêmico e social dos estudantes com deficiência, favorecendo o acesso, a permanência, a participação e a aprendizagem em instituições de ensino (BRASIL, 2015, p. 7).

Destarte, não podemos esquecer que o processo inclusivo é uma construção coletiva, que necessita do envolvimento de toda a comunidade que circunscreve a escola: alunos, professores, gestores, demais funcionários, famílias, poder público e sociedade. Para esta construção alguns ajustes ainda precisam ser feitos, pois não basta apenas inserir os estudantes com deficiência no mesmo espaço físico da escola.

Sebastián-Heredero (2010) afirma que com ações inclusivas almeja-se garantir condições para que todos os estudantes aprendam e obtenham êxito na escolarização no ensino regular. Além disso, o autor destaca que estas crianças serão escolarizadas com estudantes da mesma idade cronológica, possibilitando, portanto, a convivência em um cenário semelhante ao que se desenvolve. Para garantir isso, o acesso não é o suficiente; é preciso garantir qualidade e permanência dos estudantes com necessidades educacionais especiais desenvolvendo práticas educativas inclusivas em vários níveis, com mudanças de estratégias desde a escola até a sala de aula.

Aprofundando um pouco mais, Rodrigues (2006) discursa sobre como gerir uma sala de aula de modo inclusivo e, nesse sentido, levanta o fato de que os estudantes possam ter acesso a uma forma diferente da organização da estrutura da sala, da metodologia e do processo, a fim de que as situações de aprendizagem se diversifiquem e realmente aconteça a 
possibilidade de adequação às diferenciadas características e potencialidades dos alunos e do trabalho proposto.

\section{Fundamentação teórica}

\section{- A inclusão como conceito}

A inclusão como conceito pretende assegurar que todos os estudantes desenvolvam e aprendam nos mesmos espaços educativos e com a mesma qualidade, o que envolve modificações relevantes nas concepções escolares e docentes. Garantir o acesso à escola comum institui a parte mais simples, pois depende, primeiramente, da legislação; mas se concretiza apenas com ações nas escolas e salas de aula. O acesso a um currículo que realmente assegure o envolvimento e a aprendizagem de todos é a parte mais complexa deste processo inclusivo.

Nesta perspectiva, Ainscow e Miles (2013) apresentam a inclusão como um processo, com a finalidade de identificar e eliminar possíveis barreiras, além de assegurar a real participação e desenvolvimento com qualidade para todos, dando ênfase à escolarização dos estudantes com risco de marginalização, exclusão ou de baixo rendimento nas escolas regulares para combater a desigualdade.

A filosofia da inclusão defende uma educação eficaz para todos, sustentada em que as escolas, enquanto comunidades educativas, devem satisfazer as necessidades de todos os alunos, sejam quais forem as suas características pessoais, psicológicas ou sociais (com independência de ter ou não deficiência). Trata-se de estabelecer os alicerces para que a escola possa educar com êxito a diversidade de seu alunado e colaborar com a erradicação da ampla desigualdade e injustiça social (ARNAIZ-SANCHEZ, 2005, p. 11).

Dentro dessa visão, se considera relevante o que é entendido como um estudante que apresenta dificuldades de aprendizagem, pois esta manifestação é própria de todo ser humano em algum momento da sua vida. Nessa perspectiva, a importância não recai sobre a possível deficiência, conceito da medicina, e sim sobre as dificuldades de aprender, conceito da educação.

Os estudantes com dificuldades de aprendizagem configuram uma população muito mais ampla que os sujeitos alvo da educação especial e, muitas vezes, com iguais ou mais necessidades educativas. Para alguns dos classificados com deficiência estas dificuldades vão se apresentar de forma permanente, o que implica uma maior atenção, mas os demais alunos também merecem atenção, embora suas necessidades educativas possam ser transitórias. 
Bueno (2008) ressalta o grande erro que é considerar a inclusão no espaço educacional seja, quase exclusivamente, um sinônimo de inclusão de alunos público alvo da educação especial, como se fossem apenas esses os excluídos do e no espaço de escolarização formal.

Para que as escolas desenvolvam uma verdadeira inclusão, o processo de ensino precisa de uma revisão de modo a adequar e organizar o currículo em todos seus elementos: objetivos, conteúdos, metodologia e avaliação, tornando eles mais abertos e flexíveis a partir do respeito às singularidades de cada estudante e com respeito às suas características e condições de aprendizagem. Isso porque,

Os currículos mais equilibrados, nos quais o desenvolvimento social e pessoal também tem importância e em que a avaliação seja feita em função do progresso de cada estudante, facilitam a integração dos estudantes (COLL; PALACIOS; MARCHESI, 1995, p. 39).

\section{- A inclusão na prática}

Prática docente, segundo Gimeno Sacristán (1999), é conceituada como a cultura acumulada sobre as ações. Desse modo, é ao mesmo tempo fonte das ações e nutre-se delas:

A prática docente é a cristalização coletiva da experiência histórica das ações, é o resultado da consolidação de padrões de ação sedimentados em tradições e formas visíveis de desenvolver a atividade (p. 73).

A gênese da prática educativa está em outras práticas capazes de interagir com o sistema escolar, mantendo relação com os demais âmbitos da sociedade, por exemplo, o político, o cultural e o econômico.

Isto traz em consequência a necessidade de uma mudança importante, Pimenta (1997) aponta que as práticas pedagógicas precisam de uma ressignificação, pois segundo a autora é preciso construir novos conhecimentos sobre a didática.

Observa-se que uma re-significação da didática emerge da investigação sobre o ensino como prática social viva, nos contextos sociais e institucionais nos quais ocorre. [...] As análises apontam para a necessidade de tomar-se essa prática como ponto de partida para a construção de novos saberes sobre o fenômeno ensino (PIMENTA, 1997, p. 19-20).

Mas o foco da nossa ação é que estas práticas sejam inclusivas. Paratanto, Ainscow e Miles (2013) apresentam a inclusão como um processo, no qual é necessário que todos os estudantes com necessidades educativas aprendam e isso se traduz em práticas educativas 
inclusivas. Para conceituar as mesmas usaremos a definição dada no documento Guía para la reflexión y valoración de prácticas inclusivas:

A boa prática inclusiva deve ser entendida como uma atuação "situada", que ganha sentido e é viável a partir de uma realidade concreta, de uns condicionantes estruturais que fazem dela algo único e irrepetível (OEI, 2009, p. 5, tradução livre).

Isto nos leva a refletir sobre a singularidade das mesmas e a necessidade de contemplar propostas pedagógicas adequadas para cada contexto educativo, seja na escola ou na sala de aula, e com uma constante revisão em função do tipo de estudantes que compõem cada turma em cada ano.

Mas nem tudo que é colocado como boas práticas educativas inclusivas realmente são, pois, como Rosa, Possa e Iop (2016) advertem, elas dependem dos resultados e de como são aplicadas. Assim Booth e Ainscow (2011) referem uma dimensão no seu Índice para la inclusión chamada "Desenvolver práticas inclusivas" e colocam um conjunto de indicadores que caracterizam essas práticas educativas inclusivas:

Organizar o processo de aprendizagem:

- O planejamento e desenvolvimento das aulas responde à diversidade dos alunos.

- $\quad$ As aulas se fazem acessíveis a todos os estudantes.

- $\quad$ As aulas contribuem a uma maior compreensão das diferenças.

- $\quad$ Implica-se ativamente aos estudantes na sua aprendizagem.

- $\quad$ Os estudantes aprendem de forma cooperativa.

- A avaliação estimula os resultados de todos os estudantes.

- $\quad$ A disciplina da sala se fundamenta no respeito mútuo.

- $\quad$ Os docentes planejam, revisam e ensinam em colaboração.

- $\quad$ Os docentes se preocupam de apoiar a aprendizagem e a participação de todos os alunos.

- Os profissionais de apoio se preocupam de facilitar a aprendizagem e a participação de todos os estudantes.

- $\quad$ Os "deveres para casa" contribuem à aprendizagem de todos.

- Todos os alunos participam nas atividades complementarias e extraescolares.

Mobilizar recursos:

- $\quad$ Os recursos da escola se distribuem de forma justa para apoiar a inclusão.

- $\quad$ Conhecem e aproveitam os recursos da comunidade.

- $\quad$ Aproveita-se plenamente a experiência do pessoal da escola.

- A diversidade dos alunos se utiliza como um recurso para o ensino e aprendizagem.

- O pessoal gera recursos para apoiar a aprendizagem e a participação de todos (p. 56-57).

Nesta perspectiva inclusiva, os professores estão comprometidos a desenvolver essas práticas inclusivas e, para isso, precisam de um planejamento com detalhe das atividades e de 
um registro das mesmas com um olhar para que todos os estudantes estejam, realmente, aprendendo.

Não existe uma relação de práticas educativas que sejam catalogadas como tais, porém algumas delas são consideradas porque cumprem essa função de proporcionar alternativas de trabalho para todos os alunos quanto à forma de serem aplicadas, como visto anteriormente. Neste sentido, destacamos as discussões do Desenho Universal para a Aprendizagem - DUA (CAST, 2014), como alternativa de currículo para todos e as propostas de atividades inclusivas sejam para motivar, apresentar as informações ou para oferecer alternativas que permitam que todos os estudantes possam apresentar os aprendizados de diversas formas.

Esta perspectiva tem se mostrado possível para favorecer aos estudantes condições de aprenderem em ambientes colaborativos, os quais requerem investimentos na formação dos professores, na planificação dos currículos e da infraestrutura. Esta proposta se fundamenta nos princípios universais da acessibilidade, sem perder de referência as especificidades dos estudantes que apresentam necessidades educacionais especiais em decorrência de suas condições físicas, sensoriais, mentais ou intelectuais.

Segundo CAST (2014), o DUA se vale das contribuições das Neurociências, por entender que o cérebro é composto por um conjunto de redes em conexões, amalgamadas pelas dimensões sócio-afetivas e cognitivas, a quais possibilitam aos estudantes transformar as informações em conhecimentos e construir estratégias para organizá-las e utilizá-las para o planejamento das atividades. Para este fim, Ribeiro e Amato (2018), ao analisarem os componentes do currículo propostos por Cast (2014), informam que os objetivos, avaliações, métodos e materiais devem ser flexibilizados, conforme as orientações que seguem:

1. Objetivos: rol dos conhecimentos e habilidades que os alunos devem dominar e desenvolver.

2. Avaliação: verifica o processo de aprendizagem do aluno e faz ajustes no ensino; aponta para o currículo, não para o aluno. Verifica a evolução do aluno ao longo do percurso. Não deve oferecer um único meio de resposta e o resultado é um indicador do conhecimento.

3. Métodos: devem estar de acordo com cada rede; a) afetiva (níveis de desafios diferentes, recompensas, opções de ferramentas, contexto da aprendizagem); b) estratégica (modelos flexíveis de desempenho, feedback contínuo, prática como suporte, oportunidade de mostrar as habilidades); c) reconhecimento (fornecer vários exemplos do conteúdo, várias mídias e recursos). Os métodos devem estar de acordo com a necessidade de cada aluno e incluir todos os alunos num ambiente colaborativo.

4. Materiais: devem estar alinhados com as metas de aprendizagem; envolver os alunos para que se tornem proativos. (RIBEIRO; AMATO, 2018, p. 127). 
Em que pese as contribuições do DUA para favorecer os processos de aprendizagem para todos os estudantes, indistintamente na perspectiva que se apresenta, no entanto, há que investir muito para que as condições sejam propiciais, as quais dependem das políticas educacionais vigentes.

\section{Metodologia}

A opção escolhida para desenvolver a pesquisa foi estudo de caso que, segundo Yin (2001), é uma investigação empírica, um método que abrange planejamento, técnicas específicas de coleta de dados e análise. Além disso, o autor afirma que o estudo de caso contribui, de forma inigualável para entender os fenômenos individuais, organizacionais, sociais e políticos.

Concretamente, nos servimos dos dados facilitados pelos professores de escolas públicas estaduais e municipais de dois municípios do Estado de Mato Grosso do Sul. Pelo fato de tratar apenas com algumas escolas e não com uma amostra significativa e estratificada, a pesquisa se justifica como estudo de caso. A seleção das escolas foi feita pelas Secretarias de Educação municipais de Aquidauana e Campo Grande e Secretaria de Educação do Estado de Mato Grosso do Sul.

Esta pesquisa se caracteriza como sendo qualitativa interpretativa, pois não se tem o intuito enumerar ou mensurar os eventos pesquisados (BARDIN, 2006). Neste tipo de pesquisa não ocorre a utilização de instrumental estatístico na análise dos dados, pois o propósito não é contabilizar quantidades como resultados, e sim entender a dinâmica do comportamento de um determinado grupo pesquisado em um contexto determinado. Esta decisão foi tomada em base ao tipo de seleção de escolas e professores, pois não estamos ante uma amostra significativa.

O instrumento para a obtenção da informação foi um questionário ad-hoc (Vid. Anexo I) com seis perguntas, sendo cinco abertas e uma fechada, ao objeto de conseguir saber alguma coisa da construção da conceituação dos professores, opiniões e propostas. No total foram recolhidos 62 questionários, dos que resultaram válidos um total de 51, de seis escolas diferentes A maioria dos professores atuam no $3^{\circ}$ ou $4^{\circ}$ ano como polivalentes ou especialistas, não foram incluídos professores da educação especial nem professores de apoio; coletou-se também alguns dados de gestores e coordenadores.

Para poder entender os nossos resultados de forma qualitativa, utilizamos alguns enunciados como: a maioria dos entrevistados para referirmos a aquelas afirmações que 
aparecem em mais do que 41 dos casos; quando falamos em que muitos dos professores dizem algo se refere a expressões de entre 31 e 40 dos participantes; assim também utilizamos a metade dos pesquisados para aglutinar os dados que ficam entre 21 e 30 dos entrevistados; ainda usaremos o termo poucos educadores quando encontramos respostas desse tipo entre 11 a 20 professores; para finalizar os restantes abaixo de 10 respostas estaremos utilizando apenas alguns. Desta forma, evitamos a utilização de dados quantitativos e pelo fato de agrupar resultados em categorias qualitativas eles podem ser tomados como tendências de resultados segundo a opinião deste grupo de estudo.

Os dados, foram organizados em categorias aproximativas que abordaram os diferentes conceitos descritos pelos participantes na amostra para gerar conhecimento de como tem sido o processo de inclusão nas salas de aula, mediante a percepção dos professores, e de alguma forma conhecer os fundamentos para as práticas educativas inclusivas a partir das opiniões e sugestões.

Esta pesquisa foi submetida ao Comitê de Ética da UFMS e aprovada com o número de processo CAAE 15448919.1.0000.0021, e foram respeitados todos os aspectos éticos.

\section{Resultados}

Os resultados da pesquisa foram organizados em quatro categorias aproximativas nascidas da revisão da literatura e revisões sobre a temática. Na triangulação das informações e na construção dos nexos valeram-se também opiniões e propostas produzidas pelos participantes, as quais foram apresentadas em algumas subcategorias. As quatro categorias de análises são: Conhecimento de políticas inclusivas; Conceituação de educação inclusiva; Conceituação de alunos com dificuldades de aprendizagem; Formação docente na perspectiva da inclusão.

\section{- Sobre as políticas educativas em matéria de inclusão}

Políticas educativas são as referências efetivas às normas e instrumentos legais que definem as políticas. As políticas públicas, ao estabelecer suas ações e metas, têm como diretriz atuar no combate a qualquer desigualdade.

As políticas com foco na inclusão devem ocupar-se com a eliminação de qualquer tipo de exclusão, seja ela no espaço da escolar ou social. Com a criação das políticas públicas se 
favorece uma estrutura para modificar as relações e práticas nas diferentes instituições com foco na inclusão e com objetivo de fazer delas algo que permaneça no tempo.

Parece evidenciado, pelas respostas dos professores, que não estão muito acostumados a explicitar legislações ou normativas, exceto as nomeações da LDBEN e da Base Nacional Comum Curricular (BNCC), não foi explicitada nenhuma lei, decreto ou resolução específica.

Os comentários dos professores foram mais no sentido de questões qualitativas

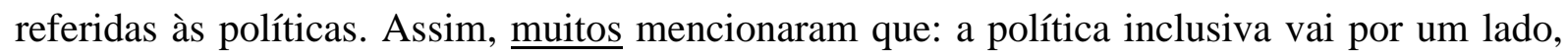
mas a prática e a realidade é outra - "A política de inclusão precisa ser mais praticada, as leis estão apenas no papel, falta muito ainda para inclusão realmente acontecer" (P-9); é uma forma de desencanto com o que viria a ser na teoria, seja por diminuição ou modificação de recursos - "Está regredindo, pois atualmente os APEs (Auxiliares de apoio educativo) foram substituídos por profissionais que não estão capacitados” (P-16); pela sensação de falta de investimento - "o governo deveria atribuir maior prioridade política e financeira para aperfeiçoar os sistemas educacionais" (P-17); a capacitação dos professores "não existe, se preocupam em colocar o aluno na escola mas não realiza a preparação dos professores incluí-lo na escola” (P-31).

Apenas alguns relacionam as políticas com o objetivo de que todos e todas aprendam em condições de igualdade, mas a simples explicitação deles já indicam que estes conhecem o caminho das mesmas, como no enunciado: "Vejo que a inclusão teve muitos avanços positivos, onde o aluno tem atendimento diferenciado e recursos para trabalhar com suas dificuldades (adequadas)" (P-44).

Há entre eles aquele que diz não haver inclusão de fato e que os estudantes com deficiências deveriam ser atendidos em instituições especiais: "Para mim não existe, acho que o aluno especial seria melhor atendido em um local especializado. Ex APAE” (P-21), um posicionamento que se distancia das atuais políticas educativas. Da mesma forma, encontramos alguns que: ou não manifestaram a sua opinião ou esta foi feita para além dos propósitos desta pesquisa.

Encontramos entre os resultados um dado importante de se ressaltar, que se refere ao fato de que, em uma das escolas, a maioria dos docentes tem um conceito negativo das políticas. Sobre isso, vale informar que as pesquisas sobre políticas educacionais informaram que no movimento da escola, elas têm dificuldades de se viabilizar em decorrência da falta de investimentos e gerenciamento dos recursos destinados para a educação. Além disso, a escola inclusiva se faz no cotidiano mediante aos desafios que se apresentam, o que torna necessário 
atenção às dimensões subjetivas que movimentam as ações e relações pedagógicas (ROSSATO; MATOS; PAULA, 2018).

\section{- Sobre a conceituação de educação inclusiva}

Quando falamos de educação inclusiva, derivado da fundamentação que embasa esta pesquisa, estamos nos referindo à educação para todos os estudantes dentro de um contexto regular, com oferta das mesmas atividades para todos independente das suas condições particulares.

O conceito que os professores possuem sobre educação inclusiva parece, em termos de pesquisa demonstra o desejo deles sobre a consolidação dos princípios da escola inclusiva, ou seja que todos os estudantes tenham êxito no processo de escolarização.

Para tanto, fizemos duas perguntas: uma com foco na educação especial e outra sobre o que entendem por educação inclusiva. Isto foi planejado assim para evitar equívocos entre os docentes e que de alguma forma se sentissem orientados para responder de forma diferente.

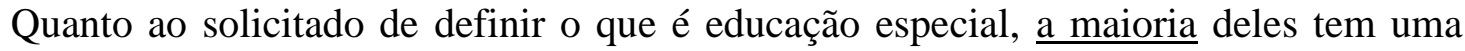
conceituação de acordo com os princípios da mesma, quer tratando do atendimento às pessoas com deficiência - "Uma educação voltada para atender uma deficiência específica, de um determinado aluno" (P-28) - quer se orientando ao atendimento dos estudantes com necessidades especiais - "Ensino destinado a alunos portadores de necessidades especiais" (P-3).

Ressaltamos de forma positiva igualmente aquelas respostas dadas apenas por alguns quando indicam que se trata de um direito - " [...] um meio de mostrar para a sociedade que o ser humano, qualquer que ele seja, tem o mesmo direito” (P-51) - ou uma ação dentro de um processo mais amplo de inclusão - "Uma ação que procura transformar através de um processo de participação de uma sociedade para promover o desenvolvimento e a aprendizagem” (P-22).

Encontramos, ainda, alguns entrevistados que nos facilitaram um tipo de resposta para a questão sobre educação especial que está próxima de posições de cuidado na perspectiva assistencial, que não educativa: "é um olhar com amor para atender aos educandos especial" $(\mathrm{P}-5)$.

Já no foco concreto da conceituação sobre educação inclusiva, a maioria tem elaborado um conceito muito próximo das propostas atuais sobre o assunto, porém ainda encontramos uns poucos que não conseguem expressar uma definição coerente com os princípios fundamentais da educação inclusiva ou manifestam desacreditar que ela realmente 
exista, o que também nos leva a refletir como pode ser a atuação deles dentro das suas salas de aula.

Dentre os que apresentam respostas acordes com a filosofia das políticas da educação inclusiva no Brasil, encontramos um grupo que afirma que se trata do atendimento dos alunos com deficiência em escolas ou salas de aula regulares - "A educação na qual incluímos o aluno especial nas aulas, eles participam da mesma aula que o aluno "normal"”, (P-24) - e outro grupo que já a especifica que é um atendimento para todos os alunos em função das suas características pessoais - " [...] um ensino de qualidade a todos os alunos, independente de sua inteligência e condições de aprendizagem" (P-37). Estas versões se dividem em correntes que defendem os princípios de educação inclusiva para todos os grupos e aquelas que são adeptas de educação segregada em instituições e/ou serviços especiais para determinados indivíduos que compõe a público alvo da educação especial. Esta percepção sectária contribui para inibir o diálogo e articulação entre os níveis, as etapas e as outras modalidades de ensino, descaracterizando o funcionamento do Sistema Educacional brasileiro. Nesta mesma linha de respostas próximas aos conceitos inclusivos, aparecem mais dois tipos, dadas por apenas alguns que ressaltam, de um lado, a filosofia desta educação " $O$ movimento de defesa dos direitos de todos os alunos a estarem juntos aprendendo” (P-22) ou "Quando sabemos da limitação de cada um e acreditamos no desenvolvimento de suas potencialidades" (P-25) - e, de outro lado, a necessidade de atuar para um movimento de "Transformação da sociedade" (P-5). Nesta compreensão, a educação inspira-se na perspectiva de correntes da pedagogia histórico-crítica, da qual Dermeval Saviani (2011) é um de seus principais representantes.

Com isto, observamos que a maioria dos professores desta amostra, seja desde posições mais filosóficas ou realmente de ações em concreto, conhecem e explicitam um conceito de educação inclusiva em consonância com as políticas públicas correlatas. Porém, ainda temos apenas alguns que a tratam como integração: "É a integração social com a comunidade escolar" (P-6).

Encontramos também, mesmo que sejam apenas alguns, os que fazem um desabafo na resposta, manifestando situações de falta de possibilidades da educação inclusiva acontecer realmente: "Vejo salas cheias, é uma utopia, principalmente com falta de recurso tanto materiais quanto humanos" (P-29). 


\section{- Sobre a conceituação de alunos com dificuldades de aprendizagem}

As dificuldades de aprendizagens resultam de vários fatores, os quais se implicam mutuamente que impactam a vida escolar dos estudantes com ou sem desenvolvimento considerado atípico. Registre-se que se forem dadas as condições necessárias para que todos possam aprender, as dificuldades vão sendo amenizadas e em algumas situações dirimidas. Nesse sentido, é necessário romper com a compreensão de que as dificuldades são decorrem de transtornos, patologias e deficiências.

Segundo já justificamos, nos pareceu relevante conhecer o que os professores desta amostra entendem por alunos com dificuldades de aprendizagem, para tanto formulamos uma pergunta que orientasse ao professor a discernir entre alunos da educação especial e alunos com dificuldades de aprendizagem.

As respostas que analisamos em este grupo de docentes refletem que todos, com exceção de um participante que não respondeu, de uma forma ou de outra, conhecem a diferença entre ambos os tipos de estudantes. Quando categorizadas estas respostas encontramos, basicamente, três alternativas: aqueles que fazem diferença no que se refere às características e competências dos estudantes, seja de forma geral - "A dificuldade na aprendizagem nem sempre está relacionada com a deficiência. Cada criança tem um ritmo de aprendizagem” (P-3) - ou específica de cada um deles - “Os alunos da Educação Especial são alunos com deficiência em algum aspecto que compromete sua aprendizagem, seja física ou cognitiva. Já os alunos com déficit de aprendizagem podem ser vários os fatores não definidos por CID, por exemplo, emocionais" (P-29).

Tudo indica que, embora o laudo não seja obrigatório para que o público alvo da educação especial tenha garantido a sua matrícula, observa-se que ele é mencionado como sendo necessário para que ela se efetive, conforme expressou um dos participantes deste estudo - "Educação especial alunos com laudo. Dificuldades de aprendizagem alunos sem laudo" (P-21). Ainda, tem-se diferenciação pelos recursos destinados aos estudantes: "Os alunos da educação especial têm direito a um professor de apoio que realiza o atendimento especializado na escola comum juntamente com o professor regente para levá-lo a aprendizagem. Sendo que os alunos com dificuldade de aprendizagem são aqueles ditos normais que a responsabilidade é do regente e desenvolver atividades adaptadas para sanar suas dificuldades de aprendizagem" (P-18). 


\section{- Sobre a formação docente na perspectiva da inclusão}

O sentido que queremos trazer aqui quando falamos em formação docente não fica restrito apenas à formação inicial, mas condicionado pela formação complementar que os professores realizam e especialmente, pela formação continuada em serviço.

Muitos professores participantes da pesquisa têm uma vasta experiência em sala de aula, pois indicam que estão atuando há mais de 10 anos, sendo que alguns deles têm mais de 20 anos de profissão. Apenas alguns têm três anos ou menos de experiência, e poucos os que têm uma atuação em sala de aula entre quatro e nove anos de experiência. Esse dado nos indica que, basicamente, estes docentes, pelo tempo em sala de aula, já viveram reformas, novas leis e, sobretudo, esta caminhada da educação inclusiva nas escolas brasileiras.

Em referência à formação dos professores, observamos que a maioria tem formação inicial em Pedagogia ou outras licenciaturas, e formação complementar em cursos de capacitação ou pós-graduação.

A pergunta sobre a formação docente foi apresentada com 12 itens ou tópicos, todos eles relativos a conteúdos que aparecem dentro da formação em educação inclusiva, para colocar se receberam ou não essa formação ou se não lembram. Destacamos, como ponto significativo, que um docente indicou que não lembrava nenhum dos tópicos descritos. Ainda, mais dois professores indicaram que não receberam nenhuma formação relacionada aos itens da pergunta; e mais outros dois que indicaram em todos os itens que não receberam formação ou não se lembram.

Os tópicos de "Conceituação e implicações da educação inclusiva", "Modelos diferenciados de avaliação dos alunos", e "Solução de conflitos/convivência entre estudantes" foram os mais lembrados como oferecidos em formação pelos docentes.

No extremo oposto tem outras três alternativas que foram lembradas por poucos docentes como trabalhadas ou apresentadas para eles em algum tipo de formação. São eles: "Realização de planos (adaptações) individualizados"; "Ensino multinível" e "Reforços, prêmios e similares".

Em outros seis conteúdos, a saber, "Características das aprendizagens das diversas deficiências e/ou necessidades educativas especiais"; "Planejamento focado na diversidade"; "Trabalho dos professores em equipe colaborativa"; "Desenho e uso de aprendizagem cooperativa com alunos"; "Estratégias de trabalho em sala de aula entre pares de alunos"; e "Uso da tecnologia para apoiar aprendizagens de estudantes com deficiência", a metade dos professores diz que os estudaram ou trabalharam dentro da sua formação docente. 
Considerando as variáveis analisadas de anos de experiência atuando como professores, formação que declaram ter e tópicos sobre os quais receberam formação, poderíamos inferir que são muitos os que deveriam ter desenvolvido competências para atender uma sala de aula com estudantes diversos dentro da perspectiva da educação inclusiva. Nessa perspectiva, na versão de Zarafian (2001), é preciso ofertar condições para que os professores desenvolvam capacidades de agirem de forma articuladas com os saberes que integram os conhecimentos, valores, motivações e a práxis.

\section{Considerações finais}

Pesquisas como a apresentada servem para conhecer a situação de um determinado coletivo de professores em um determinado contexto, e deveriam ajudar a tomar decisões sobre como atuar para melhorar a capacitação docente, de forma a possibilitar uma atuação dentro das salas de aula em consonância com os princípios da educação inclusiva, garantindo a igualdade de oportunidades de todos os estudantes e um ensino de qualidade.

Mesmo se tratando de um estudo de caso, os resultados apresentados mostram alguns dados que podem ser tomados em consideração tanto pelas políticas públicas e pela gestão educacional, quanto pela formação e a prática docente, ainda que ressalvados as suas limitações ao tratar de opiniões e manifestações.

Depois dessas ressalvas, fica explícita a necessidade de seguir trabalhando por uma educação inclusiva, já que esta é um desafio que não tem fim. Uma escola inclusiva nunca está acabada, sempre está em construção, precisando, portanto, do envolvimento de toda a comunidade educativa, para avançar rumo a uma educação de qualidade para todos.

Muitos docentes que participaram do estudo indicaram que, de alguma forma, conhecem as políticas da educação inclusiva e, mesmo sem saber explicitar de onde vem esses princípios, explicitam a filosofia ou o sentido da mesma. Destarte, tem aqueles que ainda não conseguem expressar de forma mais acertada do que se trata quando falamos de inclusão, levando o assunto a conceitos próximos da educação especial ou um descrédito da mesma. Um aprofundamento sobre os modelos que vivenciam dentro de determinadas escolas poderia ser uma hipótese de trabalho para outra pesquisa que desvendasse o porquê dessas afirmações, mesmo depois de uma caminhada tão longa pela inclusão educativa.

Fica explicitado nesta pesquisa, para a maioria dos professores participantes, que o conceito de educação inclusiva lhe é familiar, com uma diferenciação do que é educação 
especial e quais são os objetivos de cada uma delas. Observa-se nas respostas recebidas um foco nas ações de atendimento em condições de igualdade.

Da mesma forma no que já foi observado quanto às políticas, aqui também aparecem aqueles que não acreditam na educação inclusiva ou têm uma opinião de derrotismo ou impossibilidade desta ser desenvolvida. Neste sentido, fazemos a mesma observação anterior sobre a necessidade de um aprofundamento nas causas que levaram a expressar tais considerações.

Segundo os dados analisados nos questionários, parece que a maioria faz uma distinção entre os alunos da educação especial e os estudantes que apresentam dificuldades de aprendizagem, embora alguns apenas consigam elaborar a mesma a partir do laudo ou dos recursos que para os primeiros são oferecidos.

Isso parece condizente com o expressado por eles no que se refere a sua formação, já que a maioria tem uma formação complementar e a metade deles diz ter conhecimento da maioria dos tópicos de trabalho sobre educação inclusiva.

Estas considerações nos levam a pensar que este grupo de profissionais da educação, um microssistema dentro de um sistema mais amplo, apresenta uma realidade que indica a necessidade de seguir trabalhando para o conhecimento e desenvolvimento da educação inclusiva, ja que uma parcela, ainda que pequena, não acredita ou tem reticências no que se refere à inclusão.

Da mesma forma, fica constatada a necessidade de fortalecimento formativo no que diz respeito às ações pedagógicas, que ajudem a atuar concretamente na perspectiva da educação inclusiva. Isso porque, embora muitos manifestem conhecer o conceito de educação inclusiva e dificuldades de aprendizagem, nem todos têm esses conhecimentos sobre práticas educativas inclusivas.

Tais indicativos constituem-se em possibilidades investigativas, focalizadas em conhecer as práticas educativas inclusivas nas escolas de Mato Grosso do Sul, de modo a identificar suas dificuldades, seus caminhos e seus êxitos.

A devida atenção às práticas educativas inclusivas, torna-se, portanto, urgente, relevante e necessária, sendo de responsabilidade da comunidade escolar e também acadêmica. Nessa direção, acreditamos que para a construção de uma escola realmente inclusiva, é preciso muito esforço e trabalho em equipe de toda a sociedade, objetivando lograr uma qualidade na educação para todos e todas. 
AGRADECIMENTOS: Esta pesquisa está financiada por meio do programa de Professores Visitantes Estrangeiros, edital PROPP 163/2017 e sediada no PPGEDU/FAED da Universidade Federal de Mato Grosso do Sul (Brasil).

\section{REFERENCIAS}

AINSCOW, M.; MILES, S. Desarrollando sistemas de educación inclusiva. Cómo podemos hacer progressar las políticas de educación? In: Giné, C. (Coord.). La educación inclusiva. De la exclusión a la plena participación de todo el alumnado. Barcelona: Horsori Editorial, S.L. 2013. p. 23-45.

ARNAIZ-SÁNCHEZ, P. A Educação Inclusiva: um meio de construir escolas para todos no século XXI. Revista da Educação Especial. Secretaria da Educação Especial. Brasília, v. 1, n. 1, p. 7-18, 14 out. 2005.

BARDIN, L. Análise de conteúdo. Lisboa: Edições 70. 2006.

BOOTH, T.; AINSCOW, M. Index for inclusion developing learning and participation in schools. 9. ed. Bristol: Centre for Studies on Inclusive Education. 2011.

BRASIL. Lei n. 9.394, de 20 de dezembro de 1996. Diário Oficial da União, Brasília, DF, 23 dez. 1996.

BRASIL. Lei n. 13.146, de 6 de julho de 2015. Diário Oficial da União, Brasília, DF, 08 jul, 2015.

BRASIL. Declaração de Salamanca. MEC, Brasília, 1994. Disponível em: http://portal.mec.gov.br/seesp/arquivos/pdf/salamanca.pdf. Acesso em: 2 dez. 2019.

BUENO, J. G. S. A inclusão de estudantes deficientes nas classes comuns do ensino regular. Temas sobre Desenvolvimento, v. 9, n. 54, p. 21-27, 2001.

BUENO, J. G. S. As políticas de inclusão escolar: uma prerrogativa da Educação Especial? In: Bueno, J. G. S.; Mendes, G. M. L.; Santos, R. A. (Org.). Deficiência e escolarização: novas perspectivas de análise. Araraquara: Junqueira e Marin. 2008. p. 43-63.

CENTER FOR APPLIED SPECIAL TECHONOLOGY (CAST). Universal Design for Learning: theory and practice. Wakefield, MA: Cast, 2014. Disponível em: http://udltheorypractice.cast.org. Acesso em: 1 fev. 2020.

COLL, C.; PALACIOS, J.; MARCHESI, A. (Org.). Desenvolvimento psicológico e educação: necessidades educativas especiais e aprendizagem escolar. Porto Alegre: Artes Médicas, 1995.

GIMENO SACRISTÁN, J. Poderes instáveis em Educação. Porto Alegre: Artes Médicas, 1999.

ORGANIZACIÓN DE ESTADOS IBEROAMERICANOS (OEI). Guía para la reflexión y valoración de prácticas inclusivas. 2009. Disponível em:

http://www.oei.es/inclusivamapfre/Guia.pdf. Acesso em: 1 fev. 2020.

RIAEE - Revista Ibero-Americana de Estudos em Educação, Araraquara, v. 15, n. esp. 1, p. 1018-1037, maio 2020. e-ISSN: 1982-5587. 
PIMENTA, S. G. Para uma ressignificação da didática - Ciências da Educação, Pedagógica e Didática (uma revisão conceitual e síntese provisória). In: PIMENTA, S. G. (Org.) Didática e formação de professores: percursos e perspectivas no Brasil e em Portugal. São Paulo: Cortez, 1997. p. 17-30.

RODRIGUES, D. Dez ideias (mal)feitas sobre a educação inclusiva. In: RODRIGUES, D. (Org.). Inclusão e educação: doze olhares sobre a educação inclusiva. São Paulo: Summus, 2006, p. 299-318.

ROSA, D. F.; POSSA, L. B.; IOP, C. A. S. Boas práticas inclusivas: uma análise dos indicadores que transformam essas em bons experimentos inclusivos. Journal of Research in Special Educational Needs. v. 16, p. 280-284, 2016.

ROSSATO, M.; MATOS, J. F.; PAULA, R. M. de. A subjetividade do professor e sua expressão nas ações e relações pedagógicas. Educ. rev., Belo Horizonte , v. 34, e169376, 2018. Disponível em: http://www.scielo.br/scielo.php?script=sci_arttext\&pid=S010246982018000100105\&lng=en\&nrm=iso. Acesso em: 26 fev. 2020.

SAVIANI, D. Pedagogia Histórico-Crítica: primeiras aproximações. 11. ed. Campinas: Autores Associados. 2011.

SEBASTIÁN-HEREDERO, E. A escola inclusiva e estratégias para fazer frente a ela: as adaptações curriculares. Acta Scientiarum. Education, v. 32, n. 2, p. 193-208, 2010. Disponível em: http://periodicos.uem.br/ojs/index.php/ActaSciEduc/article/view/9772. Acesso em: 12 dez. 2019.

YIN, R. K. Estudo de caso: planejamento e métodos. 2. ed. Porto Alegre: Bookman, 2001. ZARIFIAN, P. Objetivo competência: por uma nova lógica. São Paulo: Atlas, 2001. 


\section{ANEXO I}

\section{QUESTIONÁRIO CONCEITOS}

Em que ano ou anos atua?

Quantos anos de experiência em sala de aula têm?

Qual é a sua formação? Especificar

Graduação: Licenciatura: Especialização: Pós-graduação:

Como você definiria, com suas palavras, Educação Especial?

Como você, com suas palavras, definiria Educação Inclusiva?

Você pode explicar, com suas palavras, a diferença entre alunos da educação especial e alunos com dificuldades de aprendizagem?

Na sua formação como docente você recebeu formação em algum dos seguintes temas, seja na inicial ou na continuada. (Marcar com X)

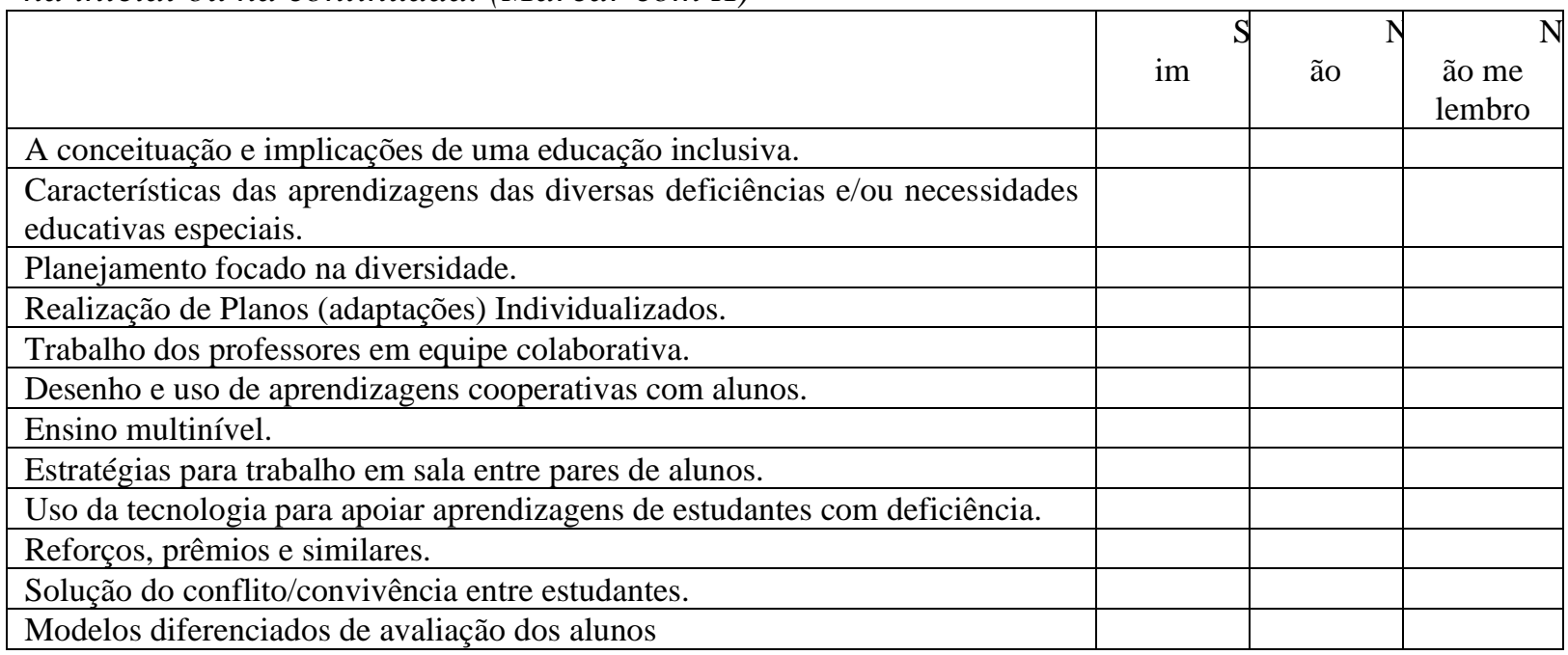

Qual é a sua opinião sobre a atual política de inclusão?

Em sua opinião o que precisaria sua escola para ser inclusiva? (Não precisa explicar, apenas elenque) 


\section{Como referenciar este artigo}

SEBASTIAN-HEREDERO, E. \& ANACHE, A. A. A percepção docente sobre conceitos, políticas e práticas inclusivas. Estudo de caso no Brasil. Revista Ibero-Americana de Estudos em Educação, Araraquara, v. 15, n. esp. 1, p. 1018-1037, maio 2020. e-ISSN: 19825587. DOI: https://doi.org/10.21723/riaee.v15iesp.1.13514

Submetido em: 11/10/2019

Revisões requeridas: 20/11/2019

Aprovado em: 28/12/2019

Publicado em: 30/04/2020 